Jurnal Indonesia Sosial Teknologi: p-ISSN: 2723 - 6609

e-ISSN : 2745-5254

Vol. 2, No. 1 Januari 2021

\title{
PEMBUATAN PROSES BISNIS PERSIAPAN MATERIAL UNTUK PRODUKSI DENGAN BUSINESS PROCESS MODELLING NOTATION (BPMN) DI PABRIK GENERATOR SETS (GENSET) PT ABC
}

\section{Daniel Tunggono Saputro}

Program Studi Teknik Informatika Universitas AKI Semarang

Email: daniel.tunggono@unaki.ac.id

\section{Abstract}

The production process is the main process of a manufacturing company. The purpose of this research is that the production process does not experience problems, so the process before production, one of which is the process of procuring materials (production materials), must be properly and accurately prepared. The material preparation process must be prepared so as not to experience material shortages or delays. The research method used by the author is to collect data from each related section and also study existing SOP. The results of this research are by using modeling techniques / diagrams BPMN can easily and clearly describe a business process so that it can be used to assist a company in carrying out business processes so that the company gets the effectiveness and efficiency of business processes

Keyword: material preparation; business process; BPMN

\begin{abstract}
Abstrak
Proses Produksi merupakan proses pokok dari sebuah perusahaan manufacture. Tujuan penelitian ini adalah agar proses produksi tidak mengalami kendala maka proses sebelum produksi yaitu salah satunya adalah proses pengadaan material (bahan produksi) harus dipersiapkan dengan baik dan tepat. Proses persiapan material harus dipersiapan agar tidak mengalami kekurangan maupun keterlambatan material. Metode Penilitian yang digunakan oleh penulis adalah melakukan pengumpulan data dari setiap bagian terkait dan juga mempejari SOP yang ada. Hasil dari penelitian ini adalah Dengan menggunakan Teknik pemodelan / diagram BPMN dapat dengan mudah dan jelas menggambarkan sebuah proses bisnis sehingga dapat digunakan untuk membantu sebuah perusahaan dalam melaksanaankan proses bisnis sehingga perusahaan tersebut mendapatkan efektivitas dan effisiensi proses bisnis.
\end{abstract}

Kata kunci: persiapa material; bisnis proses dan BPMN.

\section{Pendahuluan}

Proses bisnis produksi dalam sebuah perusahaan manufaktur merupakan proses utama dalam perusahaan tersebut. Bila proses produksi terhambat atau mengalami kekacauan maka akan menyebabkan kerugian bagi perusahaan. Proses produksi tidak boleh berhenti atau terhambat agar perusahaan tidak mengalami kerugian (Wijayanti, 2007). 


\section{Daniel Tunggono Saputro}

Salah satu proses penunjang proses produksi adalah proses pengadaan material (pengadaan bahan baku). Proses pengadaaan material harus berjalan secara baik, cepat dan tepat sehingga dapat memenuhi kebutuhan material secara tepat (jumlahnya) dan tepat waktu (sebelum digunakan untuk proses produksi) (Suwarno, 2017).

Perusahaan manufactur generator set (yang biasa disebut dengan genset) PT ABC merupakan sebuah perusahaan yang berberak dibidang perakitan (assembling) genset. Perusahaan ini melakukan proses produksi (Prasetyo, 2016). perakitan genset, sebelum perakitan genset dimulai / diproduksi maka diperlukan pengadaan material sehingga proses perakitan genset tidak mengalami kendala / terhambat.

Ada beberapa komponen pokok dalam perakitan genset ini sehingga menjadi sebuah produk akhir yang siap dijual (Munsil, 2018). Komponen - komponen utama antara lain adalah Mesin (Engine), Radiator, Generator (dinamo), Base Frame (tempat pondasi genset), dan komponen - komponen penunjang lainnya. Komponen Mesin dan Radiator, didatangkan (dibeli) dari luar negeri (import) sedangkan untuk komponen Generator, base frame dan komponen penunjang lainnya merupakan komponen yang dibeli dari dalam negeri (komponen lokal) (Weske, 2012). Komponen - komponen yang dibeli di dalam negeri ini sangat bermacam - macam (bervariasi), ada sekitar 200 macam material / barang, antara lain adalah mur dan baut dengan macam tipe dan ukuran, plat besi dengan berbagai macam ukuran, besi besi kanal, cat, amplas, dll

Pelaku dari proses pengadaaan material ini melibatkan banyak pelaku (aktor) dari berbagai bagian (departemen) sehingga harus dapat berkoordinasi dan bekerja sama dengan baik sehingga material / bahan baku dapat datang secara tepat waktu dan tidak ada kekurangan (Julyanthry et al., 2020).

Dimulai dari order dari konsumen yang dikumpulkan dan bagian marketing dan kemudian dibuat ringkasan order konsumen. Ringkasan order tersebut diberikan kepada bagian PPIC (Plan Production and Inventori Control) (Prasetyawati, Marfuah, \& Rusydi, 2018). Oleh bagian PPIC ini dibuat buatkan kebutuhan material setiap genset (daftar kebutuhan material). Jadi untuk 1 (satu) unit genset akan dibutuhkan banyak material. Dari daftar kebutuhan material maka akan didapatkan mengenai material yang tidak ada di Gudang perusahaan dan perlu dilakukan pembelian material, maka daftar ini diberikan kepada bagian pembelian untuk dapat ditindak lanjuti (Dumas, La Rosa, Mendling, \& Reijers, 2013). Jika barang yang dibutuhkan ada di Gudang maka PPIC tetap membuat daftar kebutuhan dan pengambilan barang yang diberikan ke Gudang untuk dapat ditindaklanjuti juga

Bagian Pembelian akan menindaklanjuti tentang kebutuhan material yang diberikan dari PPIC dengan membuat daftar penawaran harga yang kemudian diberikan ke Pemasok. Oleh Pemasok akan diolah dan diberikan daftar harganya dan kemudian dikembalikan lagi ke bagian Pembelian (Yuliati, 2010). Bila Bagian pembelian telah mendapatkan harga maka bagian Pembelian akan membuat PO sebagai bukti pembelian material. PO diterima pemasok kemudian dipersipakan pengiriman material dan setelah dipersiapakan materinya maka material akan kirimkan ke Perusahaan Genset ABC dan diterima oleh bagian Gudang.

Bagian Gudang yang menerima daftar kebutuhan material dari PPIC maka akan menyiapkan material-material yang ada digudang dan menunggu kekurangan material dari Pemasok. Setelah material datang dari pemasok maka material dapat didistribusikan ke bagian produksi untuk dilakukan produksi Genset (Kaihatu, 2016). 


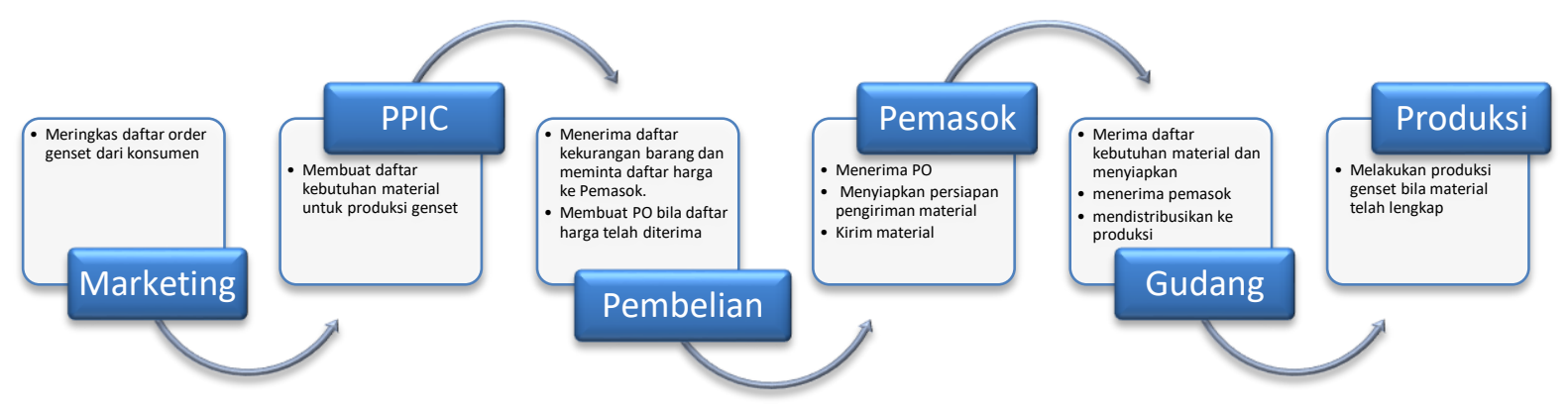

\section{Gambar 1. Proses bisnis pengadaan material sebelum produksi Pabrik Genset PT} ABC

Dibutuhkan sebuah diagram / notasi untuk menggambarkan proses bisnis pengadaan material Pabrik Genset PT ABC lebih jelas sehingga memudahkan dibaca dan diterapkan sehingga mempermudah pengadaan material untuk proses produksi Genset.

BPMN dipilih untuk menggambarkan notasi ini karena merupakan notasi yang sudah berstandar internasional dan menyediakan notasi yang mudah dipahami oleh semua pengguna bisnis, mulai dari analis bisnis yang membuat draf awal proses, hingga pengembang teknis yang bertanggung jawab untuk mengimplementasikan teknologi yang akan melakukan proses tersebut. BPMN juga menciptakan jembatan standar untuk kesenjangan antara desain proses bisnis dan implementasi proses.

(Heryanto \& Asih, 2018) telah memperlihatkan bahwa dengan menggunakan menggunakan BPMN untuk menggambarkan proses bisnis produksi donat sehingga didapatkan sebuah kesimpulan bahwa jumlah perusahaan tersebut jumlahnya tidak memerlukan penambahan dan biaya operasional dapat dikurangi jika ada integrasi metode pembayaran bagi pelanggan.

\section{Metode Penelitian}

Metode Penilitian yang digunakan oleh penulis adalah melakukan pengumpulan data dari setiap bagian terkait dan juga mempejari SOP yang ada. Setelah didapatkan metode pengumpulan data tentang SOP / alur bisnis proses, maka penulis akan menuliskan dengan diagram BPMN menggunakan perangkat lunak Bizagi Modeler.

Pengumpulan data di setiap bagian dan mempejari alur bisnis proses dari SOP yang ada, kemudian dilakukan pengamatan secara langsung dalam praktek proses bisnis.

Setelah pengamatan diyakini sudah benar, maka dilakukan penulisan diagram proses bisnis dengan diagram BPMN 2.0 di perangkat lunak Bizagi Modeler.

\section{Business Process Modelling Notatition (BPMN)}

Business Process Modeling Notation (BPMN) adalah sebuah diagram standar pemodelan untuk menggambarkan proses bisnis yang menyediakan notasi grafis dalam menjalankan proses bisnis (Ismanto, Hidayah, \& Charisma, 2020). BPMN menggambarkan sebuah proses bisnis diagram yang didasarkan kepada Teknik diagram alur, dirangkai dirangkai untuk membuat model -model grafis dari operasi-operasi bisnis 


\section{Daniel Tunggono Saputro}

dimana terdapat aktivitas - aktivitas dan control -kontrol alur yang mendefinisikan urutan kerja (Yohana, Sudarmin, Wardani, \& Mohyaddin, 2018).

Tujuan digunakan BPMN adalah adanaya notasi - notasi Teknik alur diagram yang mudah dipahami untuk membuat bisnis proses sehingga memudahkan sebuah perusahaan yang menggunakannya untuk mengambil sebuah keputusan.

BPMN dikembangkan oleh konsorsium industry (BPMI, 2006) yaitu konstituen yang mewakili berbagai vendor alat BPM tetapi bukan sebagai pembuka akhir, mengemukakan bahwa " The Business Process Modeling Notation is Emerging as a standard language for capturing business processes, e-specially at the level of domain analysis and high level systems design" (BPMI, 2006)

Berdasarakan dokumen dari omg.org yaitu formal / 2013-12-09, yang dapat maka Eelemen - Elemen dalam BPMN adalah sebagai berikut :

1. Flow Object, adalah grafik utama dari elemen - elemen BPMN yang mendefinisikan perilaku proses bisnis. Elemen - elemen Flow Bbject adalah Event, Activity dan Gateway

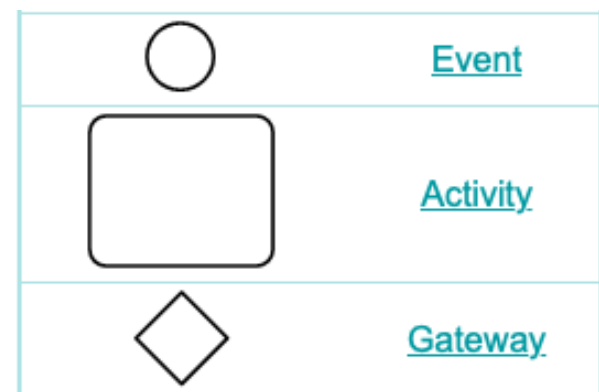

Gambar 2. Lambang Elemen dari Flow Object

(sumber gambar dari tangkap layar di https://www.bpmnquickguide.com/viewbpmn-quick-guide/)

2. Data, mempunyai elemen Data Objects, Data Inputs, Data Outputs, dan Data Stores

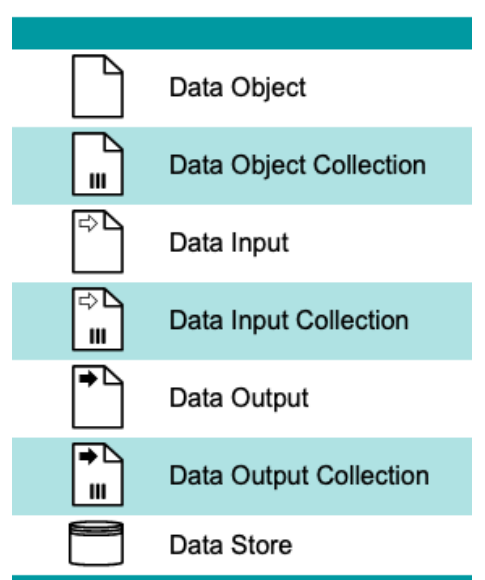

Gambar 3. Lambang Elemen dari Data

(sumber gambar dari tangkap layar di https://www.bpmnquickguide.com/viewbpmn-quick-guide/) 
Pembuatan Proses Bisnis Persiapan Material Untuk Produksi dengan Business Process Modelling Notation (Bpmn) di Pabrik Generator Sets (Genset) PT ABC

3. Connecting Object merupakan konektor yang digunakan untuk menghubungkan antar objek/proses yang terjadi, elemennya adalah Sequence Flows, Message Flows, Associations dan Data Associations

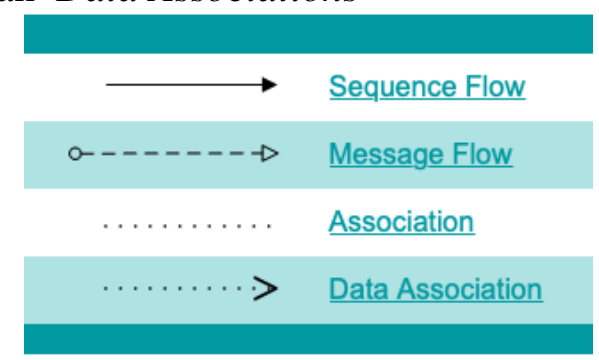

Gambar 4. Lambang Elemen dari Connecting Object

(sumber gambar dari tangkap layar di https://www.bpmnquickguide.com/viewbpmn-quick-guide/)

4. Swimlanes, merupakan pemisah yang mengatur peran/akor dari setiap proses dalam sebuah bisnis proses, terdiri dari Pool dan Lanes.

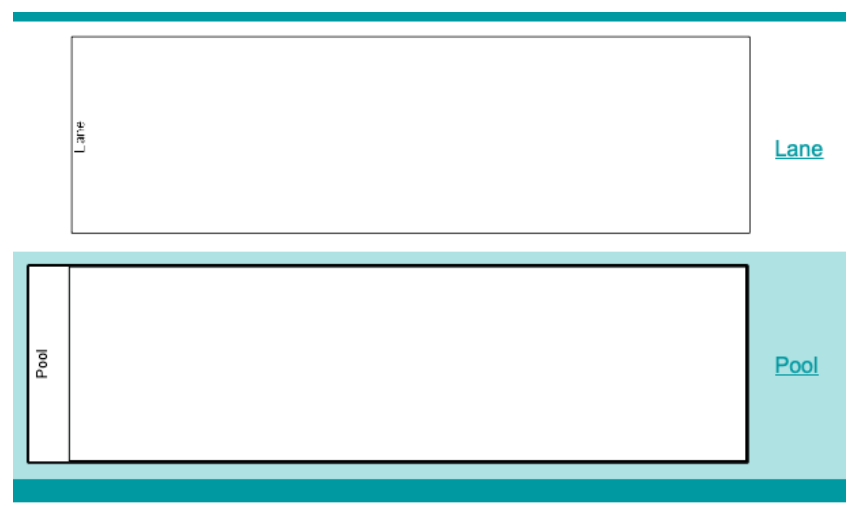

Gambar 5. Lambang Elemen dari Pool dan Lanes

(sumber gambar dari tangkap layar di https://www.bpmnquickguide.com/viewbpmn-quick-guide/)

5. Artifact, digunakan untuk memberikan informasi tambahan tentang proses. Terdiri dari Group dan Text Annotation

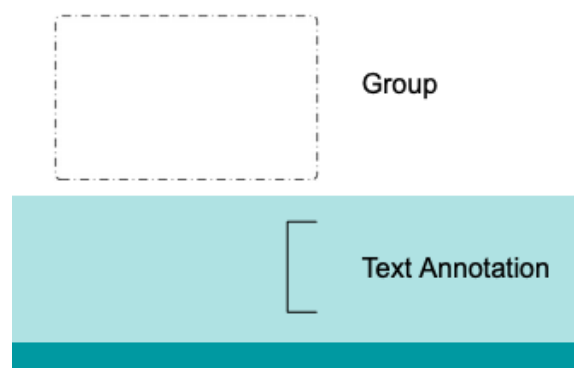

Gambar 6. Lambang Elemen dari Artifact

(sumber gambar dari tangkap layar di https://www.bpmnquickguide.com/viewbpmn-quick-guide/) 


\section{Perangkat Lunak Bizagi Modeler}

Perangkat lunak Bizagi Modeler adalah perangkat lunak yang bersifat freeware yang digunakan untuk menggambarkan diagram Business Process Modeling Notation (BPMN). Dengan perangkat lunak ini, akan didapatkan validasi apakah proses bisnis yang digambarkan ada atau tidaknya kerusakan (error) dalam pengambilan elemeneleman yang ada.

Untuk yang berbayar, Bizagi Modeler dapat digunakan untuk menghitung simulasi valiadsi proses, waktu dan harga sehingga pemakai mendapatkan informasi mengenai validitas proses yang digambarkan merupakan proses bisnis yang efektif dan efisien dalam waktu, tenaga dan biaya.

\section{Hasil dan Pembahasan}

Seperti yang sudah dijelaskan dimetode penelitian bahwa salah satu metode Penulis adalah dengan observasi wawancara, maka setelah dilakukan observasi wawancara didapatkan data kediaatan - kegiatan / peran / tugas / diskripsi pekerjaan yang dilakukan setiap bagian. Dan hasilnya dapat dilihat pada tabel 1 .

Tabel 1. Diskripsi pekerjaan pengadaan material

(sumber : data dari pabrik generator sets PT ABC)

\begin{tabular}{|c|c|c|c|}
\hline $\begin{array}{l}\text { Bagian } \\
\text { (Departemen) }\end{array}$ & Kegiatan & Penjelasan & $\begin{array}{c}\text { Estimasi } \\
\text { Waktu }\end{array}$ \\
\hline Marketing & $\begin{array}{l}\text { Membuat } \\
\text { ringkasan } \\
\text { pemesanan (order } \\
\text { genset) dari } \\
\text { Konsumen }\end{array}$ & $\begin{array}{l}\text { Setiap } 1 \text { minggu dilakukan evaluasi } \\
\text { dan ringkasan order dari konsumen } \\
\text { kemudian diberikan ke PPIC }\end{array}$ & 60 menit \\
\hline \multirow[t]{2}{*}{ PPIC } & $\begin{array}{l}\text { 1. Menerima } \\
\text { ringkasan } \\
\text { pemesanan } \\
\text { (order genset) } \\
\text { Konsumen }\end{array}$ & $\begin{array}{l}\text { Dokumen hasil ringkasan bagian } \\
\text { Marketing diterima oleh PPIC }\end{array}$ & 0 menit \\
\hline & 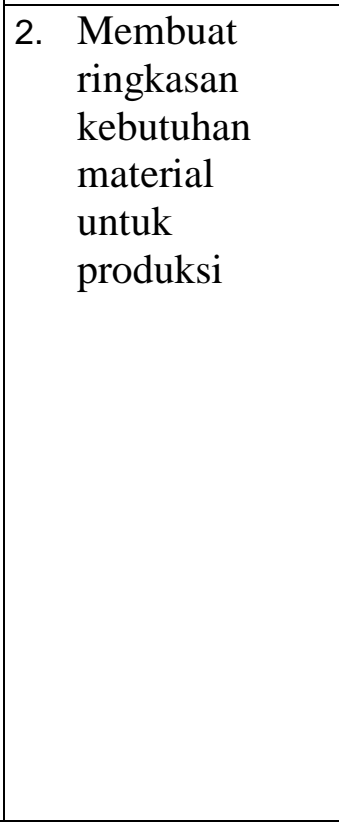 & $\begin{array}{l}\text { Setiap genset tentunya mempunyai } \\
\text { kebutuhan material yang sangat } \\
\text { banyak seperti plat, mur dan baut, } \\
\text { kabel, besi, dan banyak komponen } \\
\text { lainnya. Di proses ini adalah proses } \\
\text { yang sangat penting karena bila } \\
\text { sampai salah hitung, maka pengadaam } \\
\text { material akan salah. } \\
\text { Contohnya adalah bila produksi } \\
\text { Genset tipe ABC membutuhkan } 3 \\
\text { lembar plat } 3 \text { mm. Jika akan } \\
\text { memproduksi } 10 \text { pcs Genset tipe ABC } \\
\text { maka dibutuhkan } 30 \text { lembar plat } \\
3 \text { mm. Kebutuhan telah diketahui yaitu } \\
\text { 30 lembar. } \\
\text { Langkah berikutnya adalah melihat } \\
\text { data persediaan Gudang dan jika }\end{array}$ & $\begin{array}{l}1 \text { hari }= \\
1440 \text { menit }\end{array}$ \\
\hline
\end{tabular}




\begin{tabular}{|c|c|c|c|}
\hline & & $\begin{array}{l}\text { masih ada maka harus dilihat data } \\
\text { lagi, apakah stok tersebut sudah } \\
\text { dipesan untuk produksi yang lainnya. } \\
\text { Jika dinyatakan stok ada dan tidak } \\
\text { dipesan mana tidak dilakukan } \\
\text { pembelian. } \\
\text { Tetapi jika stok kurang akan } \\
\text { dilakukan pemebelian } \\
\text { Karena proses ini masih manual dan } \\
\text { harus memerlukan ketelitian maka } \\
\text { dibutuhkan wakti yang cukup lama. }\end{array}$ & \\
\hline & $\begin{array}{l}\text { 3. Permintaan } \\
\text { Pembelian } \\
\text { material }\end{array}$ & $\begin{array}{l}\text { Jika dibutuhkan kebutuhan material } \\
\text { karena stok di Gudang tidak ada maka } \\
\text { dilakukan pembuatan form permintaan } \\
\text { material yang kemudian diberikan ke } \\
\text { bagian Purchasing }\end{array}$ & 120 menit \\
\hline & $\begin{array}{l}\text { 4. Permintaan } \\
\text { Pengambilan } \\
\text { kebutuhan } \\
\text { material dan } \\
\text { pembuatan } \\
\text { SPK }\end{array}$ & $\begin{array}{l}\text { Jika persediaan material ada di } \\
\text { Gudang, maka PPIC membuat } \\
\text { dokumen perminataan barang dam } \\
\text { Surat Perintah Kerja (SPK) yang akan } \\
\text { diberikan ke Bagian Produksi }\end{array}$ & 120 menit \\
\hline \multirow[t]{3}{*}{ Pembelian } & $\begin{array}{l}\text { 1. Membuat } \\
\text { daftar } \\
\text { permintaan } \\
\text { harga material }\end{array}$ & $\begin{array}{l}\text { Daftar kebutuhan material dari PPIC } \\
\text { dibuatkan daftarnya dan kemudian } \\
\text { diberikan ke pemasok (Supplier) } \\
\text { untuk dimintakan daftar harganya }\end{array}$ & 120 menit \\
\hline & $\begin{array}{l}\text { 2. Menerima } \\
\text { daftar harga } \\
\text { material }\end{array}$ & $\begin{array}{l}\text { Daftar harga dari Pemasok (Supplier) } \\
\text { diterima oleh bagian Pembelian }\end{array}$ & 0 menit \\
\hline & 3. Membuat PO & $\begin{array}{l}\text { Dari daftar harga yang didapatkan } \\
\text { maka dibuat PO (Purchase Order) } \\
\text { yang dikirimkan ke Pemasok. }\end{array}$ & 120 menit \\
\hline \multirow[t]{3}{*}{ Produksi } & $\begin{array}{l}\text { 1. Menerima } \\
\text { SPK dan } \\
\text { daftar } \\
\text { kebutuhan } \\
\text { material }\end{array}$ & $\begin{array}{l}\text { Dokumen daftar kebutuhan material } \\
\text { untuk produksi Genst diterima untuk } \\
\text { digunakan pengambilan barang ke } \\
\text { Gudang dan disertakan Surat Perintah } \\
\text { Kerja (SPK) }\end{array}$ & 0 menit \\
\hline & $\begin{array}{l}\text { 2. Pengumpulkan } \\
\text { material yang } \\
\text { sudah siap } \\
\text { produksi }\end{array}$ & $\begin{array}{l}\text { Melakukan pengambilan material di } \\
\text { Gudang dan melakukan pengumpulan } \\
\text { material dan siap melakukan produksi }\end{array}$ & 0 menit \\
\hline & 3. Produksi & $\begin{array}{l}\text { Proses Produksi dimulai. Proses ini } \\
\text { sebagai proses akhir pengadaan } \\
\text { material }\end{array}$ & 0 menit \\
\hline Gudang & $\begin{array}{l}\text { 1. Penerimaan } \\
\text { barang }\end{array}$ & $\begin{array}{l}\text { Menerima barang dari Pemasok } \\
\text { setelah bagian Pembelian melakukan } \\
\text { pembelian }\end{array}$ & 120 menit \\
\hline
\end{tabular}




\begin{tabular}{|c|c|c|c|}
\hline & $\begin{array}{l}\text { 2. Pengumpulan } \\
\text { material }\end{array}$ & $\begin{array}{l}\text { Mengumpulkan material yang telah } \\
\text { ada persediannya di Gudang dan } \\
\text { material yang datang dari Pemasok }\end{array}$ & 120 menit \\
\hline & $\begin{array}{l}\text { 3. Pemberian } \\
\text { material ke } \\
\text { bagian } \\
\text { Produksi }\end{array}$ & $\begin{array}{l}\text { Setelah material terkumpulkan maka } \\
\text { material siap disistribusikan ke bagian } \\
\text { Produksi }\end{array}$ & 30 menit \\
\hline Pemasok & $\begin{array}{l}\text { 1. Menerima } \\
\text { daftar } \\
\text { permintaan } \\
\text { harga dari } \\
\text { perusahaan } \\
\text { genset PT } \\
\text { ABC }\end{array}$ & $\begin{array}{l}\text { Dokumen perminataa harga dari } \\
\text { bagian Pembelian pabrik gensets PT } \\
\text { ABC diterima oleh Pemasok }\end{array}$ & 0 menit \\
\hline & $\begin{array}{l}\text { 2. Melakuka } \\
\text { pengisian } \\
\text { daftar harga } \\
\text { yang diminta } \\
\text { oleh bagian } \\
\text { Pembelian } \\
\text { pabrik gensets } \\
\text { PT ABC }\end{array}$ & $\begin{array}{l}\text { Daftar barang tersebut diisikan daftar } \\
\text { harganya kemudian dikirimkan } \\
\text { kembali ke bagian Pembelian Pabrik } \\
\text { Gensets PT ABC }\end{array}$ & $\begin{array}{l}1680 \text { menit } \\
=1,5 \text { hari }\end{array}$ \\
\hline & 3. Menerima PO & $\begin{array}{l}\text { Setelah penawaran harga dikirimkan } \\
\text { dan ada kecocokan harga, maka } \\
\text { Pemasok akan menerima PO dari } \\
\text { Pabrik Genset PT ABC }\end{array}$ & 0 menit \\
\hline & $\begin{array}{l}\text { 4. Persiapan } \\
\text { Pengiriman } \\
\text { material }\end{array}$ & $\begin{array}{l}\text { Pemasok melakukan persiapan dan } \\
\text { pengiriman material ke Pabrik Genset } \\
\text { PT ABC }\end{array}$ & $\begin{array}{l}1440 \text { menit } \\
=1 \text { hari }\end{array}$ \\
\hline
\end{tabular}

Dari hasil observasi wawancara tersebut kemudian dilakukan pengambaran diagram / notasi bisnis proses dengan BPMN menggunakan perangkat lunak Bizagi Modeler seperti gambar 7. 
Pembuatan Proses Bisnis Persiapan Material Untuk Produksi dengan Business Process Modelling Notation (Bpmn) di Pabrik Generator Sets (Genset) PT ABC

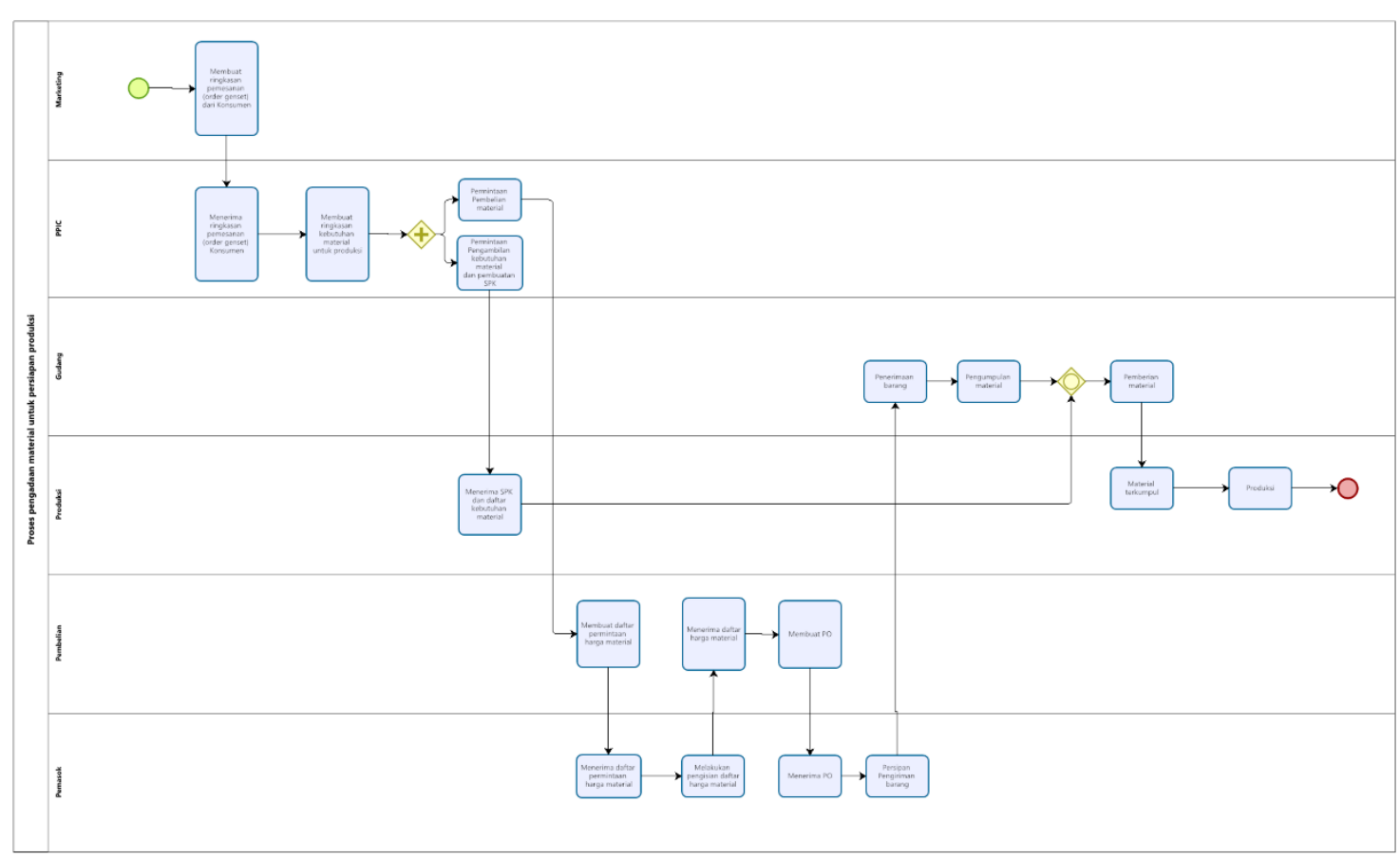

Gambar 7. Proses Bisnis pengadaan material persiapan Produksi

Dari hasil proses bisnis yang digambarkan menggunakan petangkat lunak Bizagi Modeler, kemudian dilakukan analisa dengan menggunakan fiture yang ada yaitu "Simulation View". Analisa yang dilakukan adalah

1. Analisa validasi proses

2. Analisa waktu

Analisa validasi proses adalah menganalisa mengenai apakah bisnis proses yang digambarkan sudah efektif secara pekerjaan. Artinya jika mengerjakan 10 pekerjaan, maka hasil akhirnya juga 10 pekerjaan. Jika penggambaran BPMN salah, maka analisa ini bisa melebihi dari 10 pekerjaan. Dimungkinkan ada yang salah proses sehingga dengan input 10 pekerjaan maka hasil yang dikerjakan (output) menjadi 20 pekerjaan atau lebih. Penulis sempat mengalami hal ini karena salah memasukkan eleman gateway.

Untuk analisa validasi proses, Penulis, memasukkan 1 proses karena hanya merupakan proses administrasi saja bukan merupakan proses pekerjaan. 

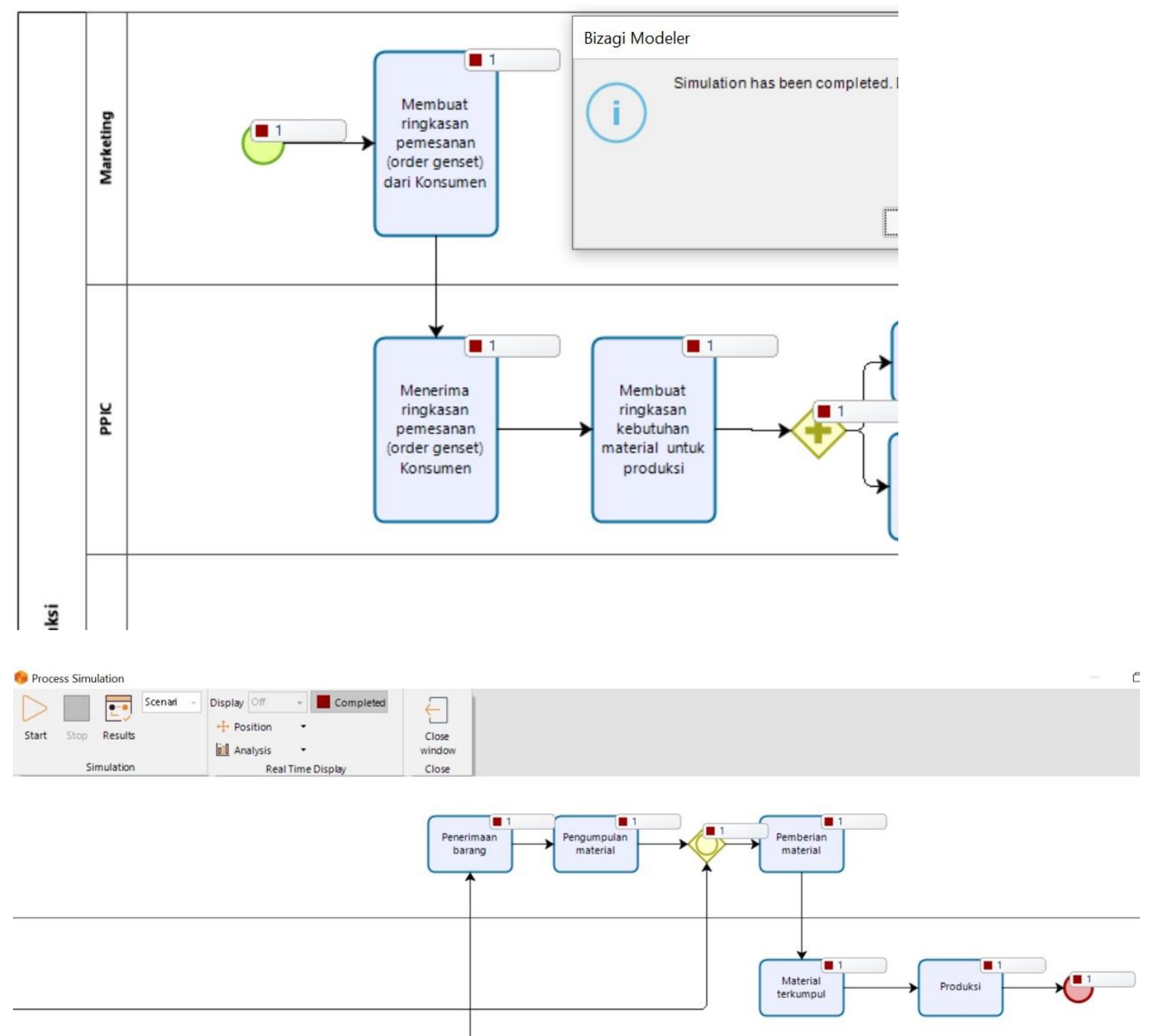

Gambar 8. Hasil analisa validasi proses yang dilihat dengan diagram 
Pembuatan Proses Bisnis Persiapan Material Untuk Produksi dengan Business Process Modelling Notation (Bpmn) di Pabrik Generator Sets (Genset) PT ABC

\section{Simulation Results}

\section{Proses pengadaan material untuk persiapan produksi}

Scenario information

Name

Time unit

Duration

Proses pengadaan matel

NoneStart

NoneEnd

\section{Gambar 9. Hasil analisa validasi proses}

Dari gambar 9, terlihat hasil simulai bahwa dengan 1 pekerjaan, yang dimulai dari NoneStart ( start event) yang berharga 1 maka akan berakhir dengan NoneEnd (End Event) bernilai 1 juga. Artinya bahwa proses binis validasi pekerjaan sudah benar.

Analisa waktu merupakan analisa berikutnya. Analisa waktu ini akan memberikan informasi mengenai waktu yang dibutuhkan dalam pengadaan proses material dari meringkas order konsumen sampai material siap produksi. Dengan melakukan simulasi “ time analysis" maka didapatkan hasil pengadaan material selama 3 hari 17 jam dan 30 menit.

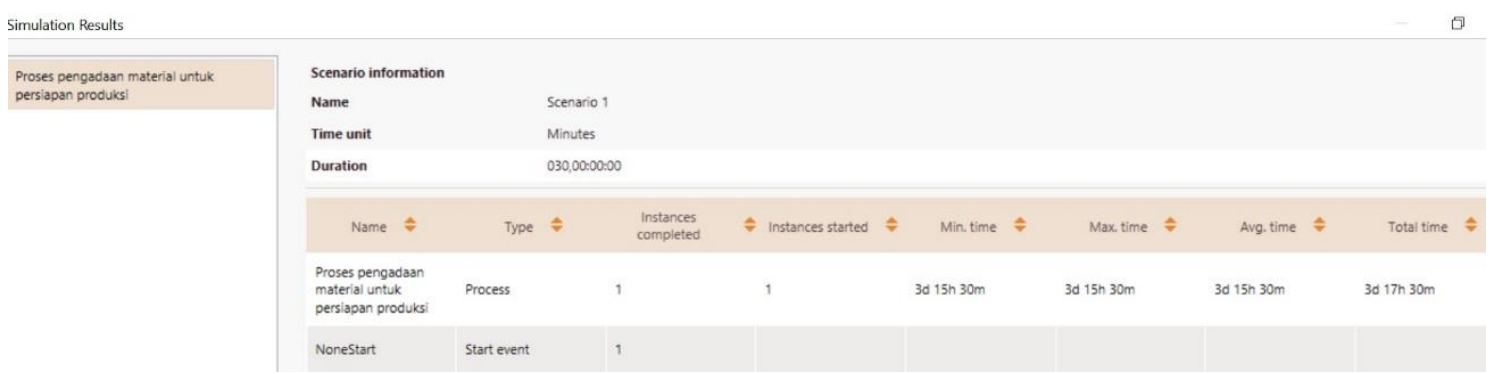

Gambar 10. Hasil analisa waktu

Setelah dilakukan evaluasi, hasil pengadaan material selama 3 hari 17 jam dan 30 menit, merupakan hasil yang harus diperbaiki karena proses ini dinilai masih terlalu lama. 


\section{Daniel Tunggono Saputro}

Dilakukan evaluasi kembali dari proses bisnis ini dengan meninjau kembali data data yang dimasukkan. Peninjauan dilakukan melalui file Excel yang didapatkan dari export hasil simulasi.

\begin{tabular}{|c|c|c|c|c|c|}
\hline - & A & $\mathrm{E}$ & $\mathrm{F}$ & G & H \\
\hline 1 & Name & Min. time (m) & Max. time (m) & Avg. time (m) & Total time (m) \\
\hline 2 & Proses pengadaan material untuk persiapan produksi & 5250 & 5250 & 5250 & 5370 \\
\hline 3 & NoneStart & & & & \\
\hline 4 & NoneEnd & & & & \\
\hline 5 & InclusiveGateway & & & & \\
\hline 6 & ParallelGateway & & & & \\
\hline 7 & Membuat ringkasan pemesanan (order genset) dari Konsumen & 60 & 60 & 60 & 60 \\
\hline 8 & Menerima ringkasan pemesanan (order genset) Konsumen & 0 & 0 & 0 & 6 \\
\hline 9 & Membuat ringkasan kebutuhan material untuk produksi & 1440 & 1440 & 1440 & 1440 \\
\hline 10 & Permintaan Pembelian material & 120 & 120 & 120 & 120 \\
\hline 11 & Permintaan Pengambilan kebutuhan material dan pembuatan SPK & 120 & 120 & 120 & 120 \\
\hline 12 & Membuat daftar permintaan harga material & 120 & 120 & 120 & 120 \\
\hline 13 & Menerima daftar harga material & 6 & 6 & 6 & 6 \\
\hline 14 & Membuat PO & 120 & 120 & 120 & 120 \\
\hline 15 & Menerima SPK dan daftar kebutuhan material & 6 & 6 & 6 & 6 \\
\hline 16 & Pengumpulan material & 120 & 120 & 120 & 120 \\
\hline 17 & Pemberian material & 30 & 30 & 30 & 30 \\
\hline 18 & Material terkumpul & 0 & 6 & 0 & 6 \\
\hline 19 & Produksi & 0 & 0 & 0 & 10 \\
\hline 20 & Menerima daftar permintaan harga material & 0 & 0 & 0 & 0 \\
\hline 21 & Melakukan pengisian daftar harga material & 1680 & 1680 & 1680 & 1680 \\
\hline 22 & Menerima PO & 0 & 0 & 6 & 0 \\
\hline 23 & Persipan Pengiriman barang & 1440 & 1440 & 1440 & 1440 \\
\hline 24 & Penerimaan barang & 120 & 120 & 120 & 120 \\
\hline
\end{tabular}

Gambar 11. Hasil analisa waktu yang di Export ke Excel

Dari data export Excel, maka didapatkan bahwa ada 3 proses yang memerlukan, waktu yang lama, yaitu

1. Proses membuat ringkasan kebutuhan material untuk produksi selama 1440 menit

2. Melakukan pengisian daftar harga material selama 1680 menit

3. Persiapan pengiriman barang selama 1440 menit.

Ada 2 proses internal (proses yang terjadi di Pabrik Genset PT ABC yang memerlukan waktu lama dalam prosesnya yaitu proses membuat ringkasan kebutuhan material untuk produksi selama 1440 menit dan melakukan pengisian daftar harga material selama 1680 menit. Proses ini lama karena masih menggunakan cara manual dalam mendapatkan datanya. Karena proses ini terjadi di internal, maka evaluasi proses bisnis dapat dengan mudah dilakukan. Diberikan usulan untuk proses bisnis yang akan datang (to-be) yaitu digunakannya sebuah Sistem informasi yang dapat menghasilkan sebuah nilai mengenai kebutuhan / kekurangan material dan menyimpan daftar harga sehingga tidak perlu melakukan permintaan daftar harga secara terus menerus. Daftar harga material tidak sering berubah, jadi bisa disimpan di dalam database dan dapat diambil kapanpun diperlukan.

Hasil dari evaluasi dan wacana untuk bisnis proses yang akan datang (to-be) atau proses bisnis yang dilakukan ReEngineering yaitu dengan mennggukana Sistem Informasi, dapat dilihat pada gambar 11. 


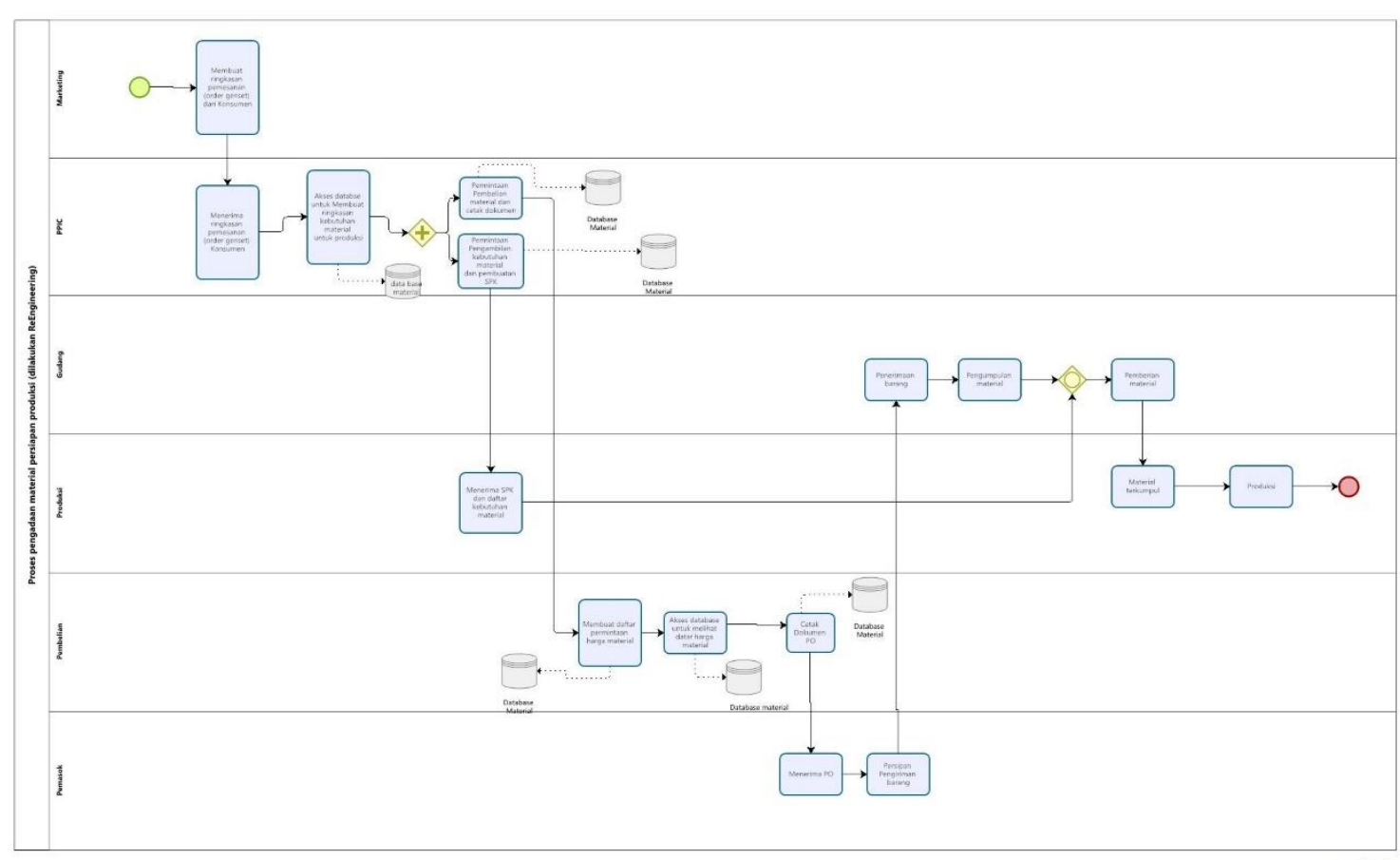

Gambar 12. Proses Bisnis pengadaan material persiapan Produksi yang dilakukan ReEngineering

Setelah dilakukan ReEngineering Proses bisnis menggunakan Sistem Infomasi akan menghasilkan:

1. Nilai kebutuhan material secara langsung dan menghasilkan dokumen / laporan kekurangan material.

2. Sistem Informasi yang terintegrasi maka bagian Pembelian akan dnegan mudah mengambil data material yang dibutuhkan / kekurangan material dari PPIC dan kemudian dibuatkan PO.

3. Proses permintaan daftar barang dihilangkan karena di dalam database tersedia data harga dan mengemat waktu proses pengadaan material.

Proses bisnis telah selesaikan digambarkan, maka dilakukan simulasi waktu kebutuhan pengadaan barang, didapatkan waktu selama 1 hari 11 jam dan 41 menit.

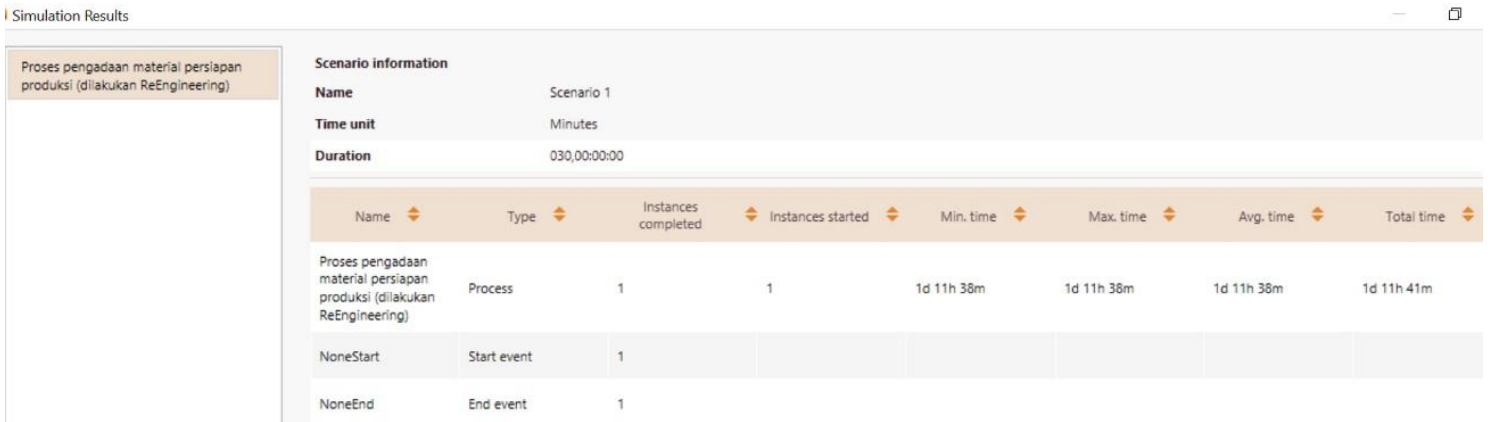

Gambar 13. Hasil analisa waktu ReEngineering dengan Sistem Informasi

Waktu pengadaan selama 1 hari 11 jam dan 41 menit dinilai sudah baik karena diperlukan waktu bagi pemasok untuk menmpersiapkan dan pengiriman material. 


\section{Daniel Tunggono Saputro}

\section{Kesimpulan}

Dengan menggunakan Teknik pemodelan / diagram BPMN dapat dengan mudah dan jelas menggambarkan sebuah proses bisnis sehingga dapat digunakan untuk membantu sebuah perusahaan dalam melaksanaankan proses bisnis sehingga perusahaan tersebut mendapatkan efektivitas dan effisiensi proses bisnis.

Perangkat lunak Bizagi Modeller dapat dengan mudah dioperasikan sehingga didapatkan hasil yang dapat dilakukan evaluasi bagi perusahaan genset PT ABC.

Untuk proses bisnis (to-be) yaitu penggunaan Sistem Informasi diusulkan secepatnya dilakukam implementasi agar didaptkan penghematan waktu sehingga akan menghemat biaya produksi 
Pembuatan Proses Bisnis Persiapan Material Untuk Produksi dengan Business Process Modelling Notation (Bpmn) di Pabrik Generator Sets (Genset) PT ABC

\section{Bibliografi}

BPMI. (2006). BPMI.org. Retrieved from BPMI.org

Dumas, Marlon, La Rosa, Marcello, Mendling, Jan, \& Reijers, Hajo A. (2013). Business process management. Springer.

Heryanto, Deni, \& Asih, Vemy Suci. (2018). BUSINESS PROCESS MODEL AND NOTATION (BPMN) DONAT MADU CIHANJUANG. INTERNAL (Information System Journal), 1(1), 11-18.

Ismanto, Ismanto, Hidayah, Firman, \& Charisma, Kristinanti. (2020). Pemodelan Proses Bisnis Menggunakan Business Process Modelling Notation (BPMN)(Studi Kasus Unit Penelitian Dan Pengabdian Kepada Masyarakat (P2KM) Akademi Komunitas Negeri Putra Sang Fajar Blitar). Briliant: Jurnal Riset Dan Konseptual, 5(1), 69-76.

Julyanthry, Julyanthry, Siagian, Valentine, Asmeati, Asmeati, Hasibuan, Abdurrozzaq, Simanullang, Ramses, Pandarangga, Adi Papa, Purba, Sukarman, Purba, Bonaraja, Pintauli, Rolyana Ferinia, \& Rahmadana, Muhammad Fitri. (2020). Manajemen Produksi dan Operasi. Yayasan Kita Menulis.

Kaihatu, Thomas Stefanus. (2016). Manajemen Supply Chain Pada Industri Global.

Munsil, Derry Perdana. (2018). Dasar Manajemen Konstruksi Proyek Jalan:(Tatahapn Pre-Start). Deepublish.

Prasetyawati, Meri, Marfuah, Umi, \& Rusydi, Adi Rofi. (2018). UPAYA MEMINIMASI PEMBOROSAN DI DEPARTEMEN PRODUKSI PT. DANA PAINT INDONESIA MENGGUNAKAN METODE LEAN MANUFACTURING. Prosiding Semnastek.

Prasetyo, Taufan. (2016). Analisis Potensi Peningkatan Tkdn Untuk Mendukung Daya Saing Industri Galangan Kapal Dalam Negeri. Institut Teknologi Sepuluh Nopember.

Suwarno, Agus. (2017). Perancangan Sistem Informasi Pengadaan Bahan Baku Produksi Pada PT. Kohno Indonesia. Jurnal SIGMA, 6(1), 81-88.

Weske, Mathias. (2012). Business process management architectures. In Business Process Management (pp. 333-371). Springer.

Wijayanti, Ika Yuli. (2007). Pengaruh Modal Kerja Dan Perputaran Modal Kerja Terhadap Return On Equity (ROE) Pada Perusahaan Manufaktur Yang Terdaftar Di Bursa Efek Jakarta. Universitas Negeri Semarang.

Yohana, Ismi, Sudarmin, Sudarmin, Wardani, Sri, \& Mohyaddin, Siti. (2018). The generic science skill profile of fourth grade students on acid and base topic in guided inquiry learning model. International Journal of Active Learning, 3(2), 110-116. 


\section{Daniel Tunggono Saputro}

Yuliati, Dewi. (2010). Mekanisme sales contract process outdoor furniture ke pasar eropa pada CV Nova Furniture Boyolali.

https://www.bpmnquickguide.com

https://www.omg.org

https://help.bizagi.com/process-modeler/en/index.html?intro_resources.htm 